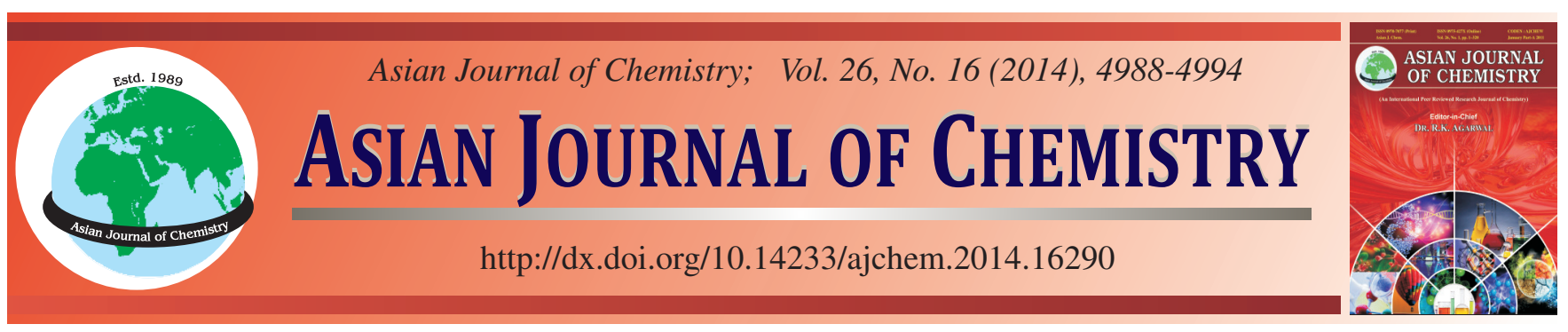

\title{
Synthesis of Nano-Sized Protonic Acid Catalyst and Initial Kinetic Study of Esterification Reaction of Methanol with Acetic Acid
}

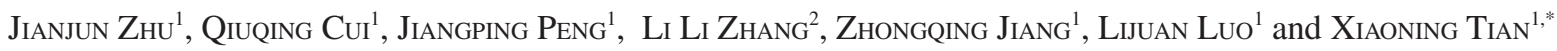

${ }^{1}$ Department of Chemistry Engineering, Ningbo University of Technology, Ningbo 315016, P.R. China

${ }^{2}$ Department of Chemical and Biomolecular Engineering, National University of Singapore, 4 Engineering Drive 4, 117576, Singapore

*Corresponding author: Tel/Fax: +86 574 87081204; E-mail: boxertxn@ hotmail.com

\begin{abstract}
Nano-sized protonic acid catalysts were synthesized and their catalytic properties in the esterification reaction over methanol whith acetic acid were evaluated. The surface chemistry of the synthesized catalysts was investigated using solid-state magic-angle spinning nuclear magnetic resonance, X-ray photoelectron spectroscope and elemental analysis techniques (CHNS-O). The results showed that the appropriate increment of sulfonation temperature can facilitate the attachment of $-\mathrm{SO}_{3} \mathrm{H}$ groups and also benefit for the enhancement of acetic acid conversion. The initial kinetic study of esterification reaction of methanol and acetic acid, which was catalyzed by synthesized nano-sized protonic acid catalysts, indicates that only one active site was involved in the surface reaction and thus the initial reaction mechanistic paths under our reaction conditions were proposed.
\end{abstract}

Keywords: Nano-sized protonic acid catalyst, Polystyrene nanospheres, Esterification reaction, Initial kinetic study.

\section{INTRODUCTION}

Organic esters are important fine chemicals widely used in the manufacturing of pharmaceuticals, flavors and plasticizers, etc. They are also used as emulsifiers in the food and cosmetic industries. The most-used way for ester synthesis is direct esterification of carboxylic acids with alcohols in the presence of strong mineral acid, such as sulfuric acid. However, the use of liquid sulfuric acid leads to inevitable problems, such as safety and difficulty of separation from the reaction medium. Therefore, solid acid catalysts based on silicas ${ }^{1-5}$, organic/inorganic solid hybrids ${ }^{6-10}$ and carbons ${ }^{11,12}$ have been widely explored over the past decade.

Introducing sulfonic acid group $\left(-\mathrm{SO}_{3} \mathrm{H}\right)$ on organic-based materials is more desirable because the organic-based materials in general exhibit hydrophobic features, thus favorable for hydrocarbon conversion reactions ${ }^{13}$. Esterification involved carboxylic acids with alcohols was carried out by using sulfonated alkylated polystyrene as solid acid catalyst. And the highly hydrophobic nature of the resultant polymer based sulfonic acid catalyst played a very important role for activity in the esterification reaction ${ }^{14}$. However, the stability and recycleability of sulfonated polystyrene should be further evaluated for practical application and the related research work was limited. Sulfonated polystyrene nanospheres, which show excellent stability and recycleability, have been reported in our previous research work ${ }^{15}$. Moreover the relationship between material structure and attached acid groups was investigated. Through the design of material structure, resultant acid catalyst can show different catalytic properties.

In this work, continuing with our previous research work, nano-sized protonic acid catalysts were synthesized. It was observed that synthesized nano-sized protonic acid catalysts show better acid conversion capability than commerical solid acid catalyst. Moreover, the catalysts prepared with a sulfonation temperature of $80^{\circ} \mathrm{C}$ exhibited the highest acid conversion and best recycleability. The initial kinetic study of the esterification reaction over methanol with acetic acid catalyzed by prepared strong nano-sized protonic acid catalyst was investigated and the result showed that only one active site was involved in the surface reaction.

\section{EXPERIMENTAL}

Sulfuric acid (98\%, Merck), styrene (99\%, Alfa Aesar), divinylbenzene (DVB) (80\% mixture of isomers, Aldrich), potassium presulfate (KPS) (Aldrich). In this work, nano-sized crosslinking polystyrene spheres (NCPSs) were synthesized using the emulsifier-free emulsion polymerization method. The nano-sized protonic acid catalyst was prepared through sulfonation reaction of nano-sized crosslinking polystyrene spheres. 
Synthesis of nano-sized crosslinking polystyrene spheres: The synthesis of nano-sized cross linking polystyrene spheres was conducted following the method described previously ${ }^{16}$. Styrene monomer $(21.4 \mathrm{~mL})$ and $0.8 \mathrm{~mL}$ divinylbenzene were combined with $200 \mathrm{~mL}$ of dionized water. The mixture was stirred at $60{ }^{\circ} \mathrm{C}$ under the protection of nitrogen for $1 \mathrm{~h}$. Then, $0.14 \mathrm{~g}$ potassium presulfate was dissolved in $50 \mathrm{~mL}$ of dionized water and then was added to the mixture under stirring at $60^{\circ} \mathrm{C}$ for $30 \mathrm{~h}$. The final solids were collected by centrifuge and dried at $60^{\circ} \mathrm{C}$ in an oven. The diameter of prepared nano-sized crosslinking polystyrene spheres is shown in Table-1.

\begin{tabular}{lccccc}
\multicolumn{7}{c}{ TABLE 1 } \\
\multicolumn{7}{c}{ PREPARATION PARAMETERS AND } \\
DIAMETERS OF RESULTANT NANO-SIZED SPHERES \\
\hline \multirow{5}{*}{ Sample } & $\begin{array}{c}\text { Styrene } \\
\text { Amount } \\
(\mathrm{g})\end{array}$ & $\begin{array}{c}\text { Divinyl- } \\
\text { benzene } \\
(\mathrm{mL})\end{array}$ & $\begin{array}{c}\text { Potassium } \\
\text { persulfate } \\
(\mathrm{g})\end{array}$ & $\begin{array}{c}\text { Sulfonation } \\
\text { temperature } \\
\left({ }^{\circ} \mathrm{C}\right)\end{array}$ & $\begin{array}{c}\text { Diameter } \\
(\mathrm{nm})\end{array}$ \\
\hline NCPSs (0.8) & 19.6 & 0.8 & 0.14 & - & 446 \\
SNCPSs (40) & 19.6 & 0.8 & 0.14 & 40 & 441 \\
SNCPSs (80) & 19.6 & 0.8 & 0.14 & 80 & 465 \\
SNCPSs (100) & 19.6 & 0.8 & 0.14 & 100 & 494 \\
\hline NCPSs: nano-sized crosslinking polystyrene spheres; SNCPSs: \\
sulfonated nano-sized scrosslinking polystyrene sphere
\end{tabular}

Synthesis of nano-sized protonic acid catalyst: About $3 \mathrm{~g}$ of nano-sized crosslinking polystyrene spheres were combined with $60 \mathrm{~mL}$ of concentrated $\mathrm{H}_{2} \mathrm{SO}_{4}$ at a given temperature. After $24 \mathrm{~h}$, the sample was cooled down to room temperature. The solids were washed with deionized water repeatedly to ensure no sulfate ions were detectable in the filtrate. The resultant nano-sized protonic acid catalysts were donated as nanosized protonic acid catalyst (x), where $\mathrm{x}$ stands for sulfonation temperature. The diameters of prepared nano-sized protonic acid catalyst were exhibited in Table-1.

Detection method: Solid-state magic-angle spinning nuclear magnetic resonance (MAS-NMR) spectra were collected on a Bruker DRX400 MHz FT-NMR spectrometer. X-ray photoelectron spectroscopy (XPS) spectra were recorded on an AXIS HIS 165 spectrometer (Kratos Analytical) with a monochromatized AlK $\alpha$ X-ray source. The elemental compositions of the samples were detected using a CHNS-O analyzer (FLASH EA 1112 series, Thermo electron corporation). The catalytic performance of prepared nano-sized protonic acid catalyst was evaluated using the esterification reaction between methanol and acetic acid. The reaction was carried out in a round bottom flask immersed in a silicon oil bath at $55^{\circ} \mathrm{C} .1$ mol of methanol, $0.1 \mathrm{~mol}$ of acetic acid and $0.2 \mathrm{~g}$ of catalyst were added into the flask. Quantitative analysis was carried out after $5 \mathrm{~h}$ of reaction using a gas chromatograph (HP 6890 series GC) mass spectrometer (HP 5973 Mass selective detector) with a capillary column $(\mathrm{HP} 5 \mathrm{MS}, \mathrm{L}=30 \mathrm{~m}$, I.D. $=0.25 \mathrm{~mm}$, film thickness $=0.25 \mathrm{~mm}$ ). The used catalyst was collected, washed using dionized water and dried at $60^{\circ} \mathrm{C}$ for the next reaction run.

\section{RESULTS AND DISCUSSION}

MAS NMR and XPS spectra: Fig. 1 shows the ${ }^{13} \mathrm{C}$ NMR spectra of prepared nano-sized crosslinking polystyrene-

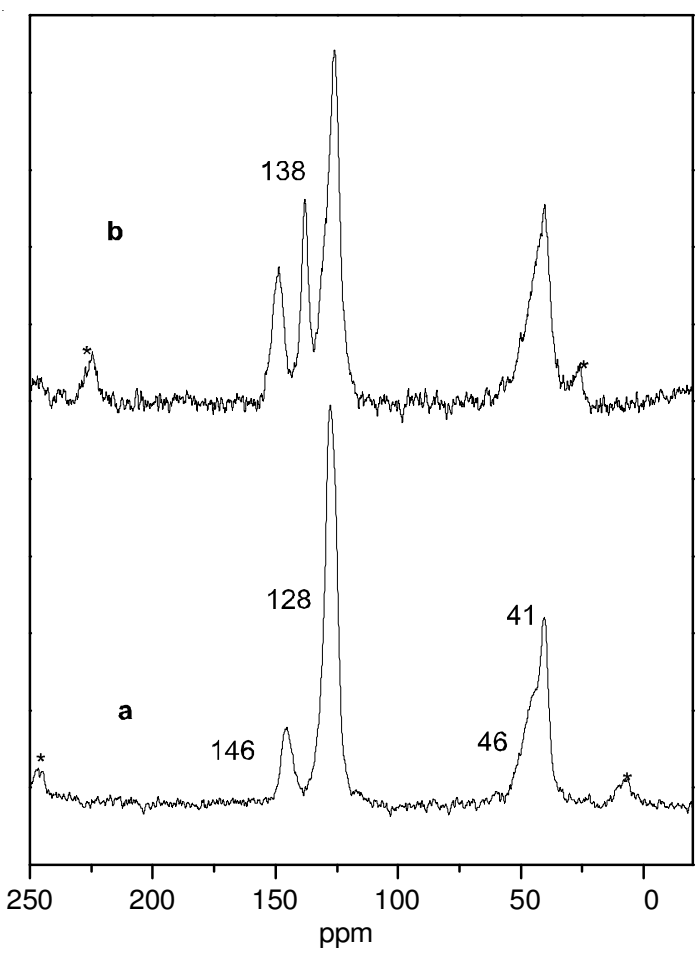

Fig. 1. ${ }^{13} \mathrm{C}$ MAS NMR spectra for (a) nano-sized crosslinking polystyrene spheres, (b) sulfonated nano-sized crosslinking polystyrene spheres (80) (*spinning side bands)

spheres and nano-sized protonic acid catalyst (80). The resonances at 41 and $46 \mathrm{ppm}$ for nano-sized crosslinking polystyrene spheres were assigned to methylene $\left(-\mathrm{CH}_{2}^{-}\right)$and methane (-CH-) carbon, respectively ${ }^{17,18}$. At the same time, the resonances at 146 and 128 ppm were ascribed to non-protonated and protonated aromatic carbons ${ }^{17,18}$. After sulfonation reaction an additional ${ }^{13} \mathrm{C}$ NMR signal was found out with chemical shift at about $138 \mathrm{ppm}$, which was attributed to the sulfonated aromatic carbon ${ }^{17,18}$, indicating the attachment of $-\mathrm{SO}_{3} \mathrm{H}$ groups.

The chemical shifts assigned to $-\mathrm{CH}_{2}$ - and $-\mathrm{CH}$ - carbon for nano-sized protonic acid catalyst (80) were similar compared to that of nano-sized crosslinking polystyrene spheres, which indicated that the local structure of prepared nano-sized crosslinking polystyrene spheres was only slightly influenced by the presence of the sulfonic acid group, indicating the well maintenance of the polymer backbone after sulfonation process for the nano-sized protonic acid catalyst.

The attachment of $-\mathrm{SO}_{3} \mathrm{H}$ groups onto the aromatic carbon atoms can also be testified by XPS technique. The XPS spectra for nano-sized protonic acid catalyst (40) and nano-sized protonic acid catalyst (80) are shown in Fig. 2. All samples exhibited a single S2p peak at about $168.6 \mathrm{ev}$, which is assigned to the aromatic carbon atoms in connection with $-\mathrm{SO}_{3} \mathrm{H}$ groups $^{11,19}$. The $\mathrm{S} 2 \mathrm{p}$ spectra can be deconvoluted into two peaks with binding energies of 168.5 and $169.7 \mathrm{ev}$, which are assigned to $\mathrm{S} 2 \mathrm{p} 3 / 2$ and $\mathrm{S} 2 \mathrm{p} 1 / 2$ of the sulfur in $-\mathrm{SO}_{3} \mathrm{H}$, respectively $^{18,20,21}$.

Sulfur content investigated by elemental analysis: As shown in Fig. 3, the $\mathrm{S}$ content for the resultant samples increased initially with the increase of sulfonation temperature and then decreased with the continuous increment of sulfonation 

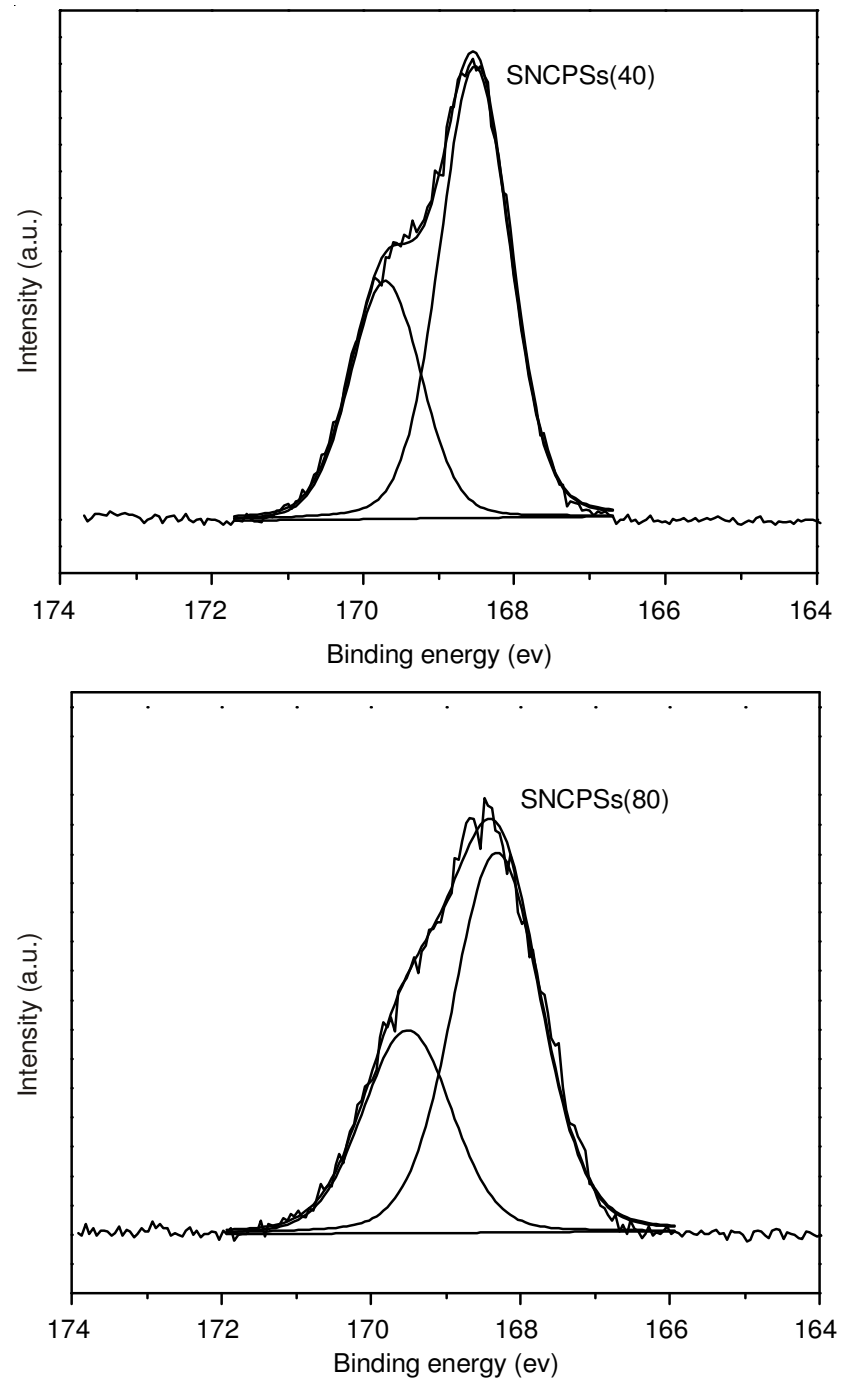

Fig. 2. S2p XPS spectra for SNCPSs (40) and SNCPSs (80)

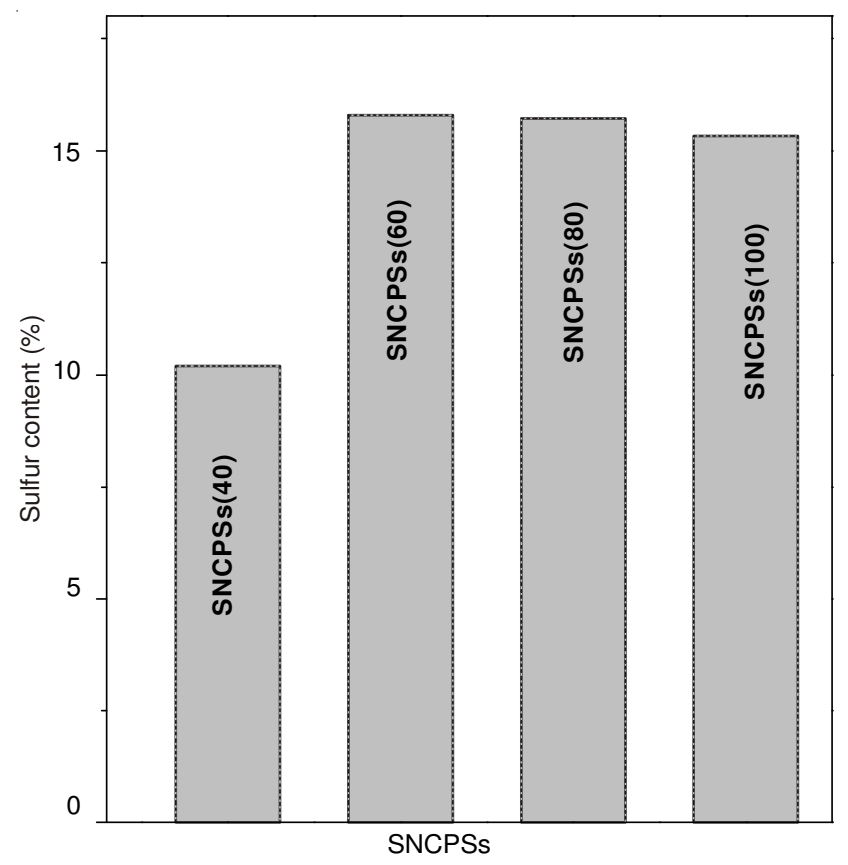

Fig. 3. S content obtained from elemental analysis for SNCPSs temperature. Since sulfur exits only in the form of $-\mathrm{SO}_{3} \mathrm{H}$, high sulfur content indicates large amount of attached $-\mathrm{SO}_{3} \mathrm{H}$ groups and high acidity for nano-sized protonic acid catalyst. It can be assumed that the appropriate increment of sulfonation temperature can facilitate the attachment of $-\mathrm{SO}_{3} \mathrm{H}$ groups onto the nano-sized crosslinking polystyrene spheres.

Catalytic performance: It can be seen from Fig. 4 that all nano-sized protonic acid catalyst show high acetic acid conversion efficiency even after the $4^{\text {th }}$ reaction run. Moreover, the same mass of commercial strong acid catalyst Amberlyst15 was also evaluated at the same reaction conditions. However, the conversion of acetic acid for Amberlyst-15 is 58 $\%$, which is lower than that of nano-sized protonic acid catalyst. Therefore, we can conclude that the prepared nano-sized catalysts are strong protonic acid catalysts.

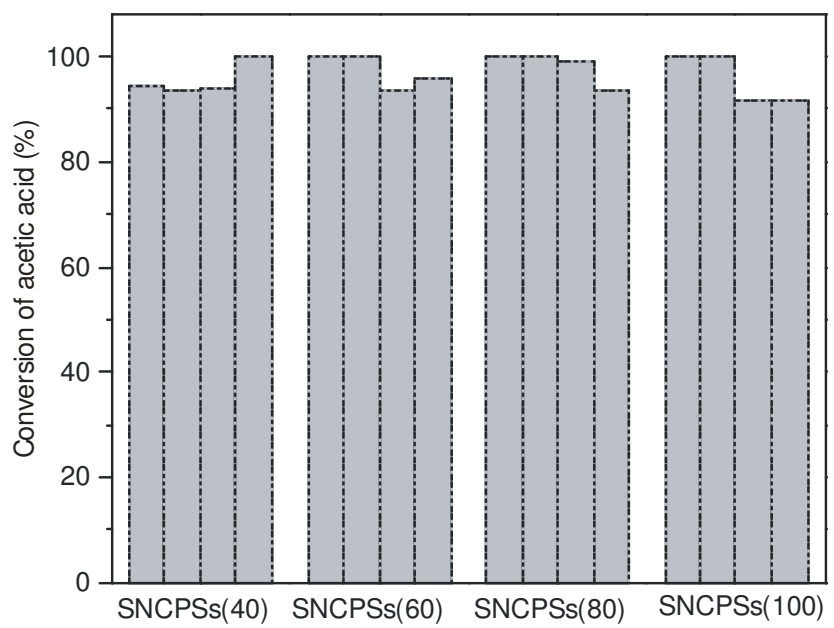

Fig. 4. Catalytic conversion of acetic acid for four reaction runs over SNCPSs (40), SNCPSs (60), SNCPSs (80) and SNCPSs (100). (Four columns indicate the $1^{\text {st }}$ to $4^{\text {th }}$ reaction run)

Initial kinetic study: The initial kinetic study of the esterification reaction over methanol with acetic acid in this work was also investigated. Sample nano-sized protonic acid catalyst (80) shows the best conversion efficiency and recyclability among all the resultant catalysts. Therefore, the esterification reaction catalysed by nano-sized protonic acid catalyst (80) was chosen for the initial kinetic study target.

Effect of polymer swelling and stirring speed: In the initial kinetic study process, reagents were heated to the desired temperature before the reaction. Once the desired temperature was reached, the esterification reaction was started upon addition of the catalyst.

Nano-sized protonic acid catalyst (80) is a polymer based catalyst, therefore, swelling of the polymer in polar solvent is known to occur ${ }^{21}$. Even slight swelling of the catalyst could affect the catalytic activity because additional acid sites can be exposed during swelling process, which will lead to inaccurate kinetic measurement. In order to determine whether swelling played a role in conversion, two sets of experiments were carried out. First, nano-sized protonic acid catalyst (80) was presoaked in methanol overnight before the reaction. Methanol was used as the soaking solvent because acetic acid has much less capability to swell the polymeric resin than methanol ${ }^{22}$. 
The esterification reaction was then initiated by charging the acetic acid. On the other hand, another experiment was carried out by direct addition of the catalyst without the presoaking condition. The initial reaction rates (a particular instantaneous rate, the rate of reaction just after the reactants are mixed is called the initial reaction rate) obtained from the above two experiments were listed in Table-2. It can be seen that nearly identical reaction rates were obtained, which confirmed that the swelling of the catalyst due to methanol had a negligible effect on the initial reaction rate.

\begin{tabular}{|c|c|c|c|}
\hline \multicolumn{4}{|c|}{$\begin{array}{c}\text { TABLE-2 } \\
\text { INITIAL REACTION RATE BY USING CATALYST } \\
\text { WITH/WITHOUT SWELLING IN METHANOL }\end{array}$} \\
\hline SNCPSs (80) & $\mathrm{C}_{\mathrm{A} 0}(\mathrm{~mol} / \mathrm{L})^{\mathrm{a}}$ & $\mathrm{C}_{\mathrm{M} 0}(\mathrm{~mol} / \mathrm{L})^{\mathrm{b}}$ & $\mathrm{r}_{0}(\mathrm{~mol} / \mathrm{L} * \min ) * 100^{c}$ \\
\hline $\begin{array}{l}\text { With swelling in } \\
\text { methanol overnight }\end{array}$ & 10 & 10 & 1.0 \\
\hline $\begin{array}{l}\text { Without swelling } \\
\text { in methanol }\end{array}$ & 10 & 10 & 1.1 \\
\hline
\end{tabular}

Since the kinetic study required the reaction to be operated at the kinetically controlled regime, the diffusion limitations were ruled out by varying the stirring speed between $0-1250$ $\mathrm{rpm}$. Since the particle size of the catalyst sample nano-sized protonic acid catalyst (80) is small (about $465 \mathrm{~nm}$ ), it can be dispersed in the reactant mixtures homogeneously. In addition, it is non-porous material. Hence, the effect of particle size and the pore diffusion was not involved. The initial reaction rates under different stirring speed were shown in Fig. 5. It can be seen that no obvious change was found in initial reaction rate under different reaction stirring speed. Therefore, a stirring speed of $1250 \mathrm{rpm}$ was used in the initial rate studies to rule out the diffusion limitation. In our experiment the catalyst was not prepared in pellets, therefore, the investigation of the effect of particle size on initial reaction rate was not involved.

The catalytic reaction runs were carried out under the kinetically controlled regime with the exclusion of polymer swelling, stirring speed and particle size effect.

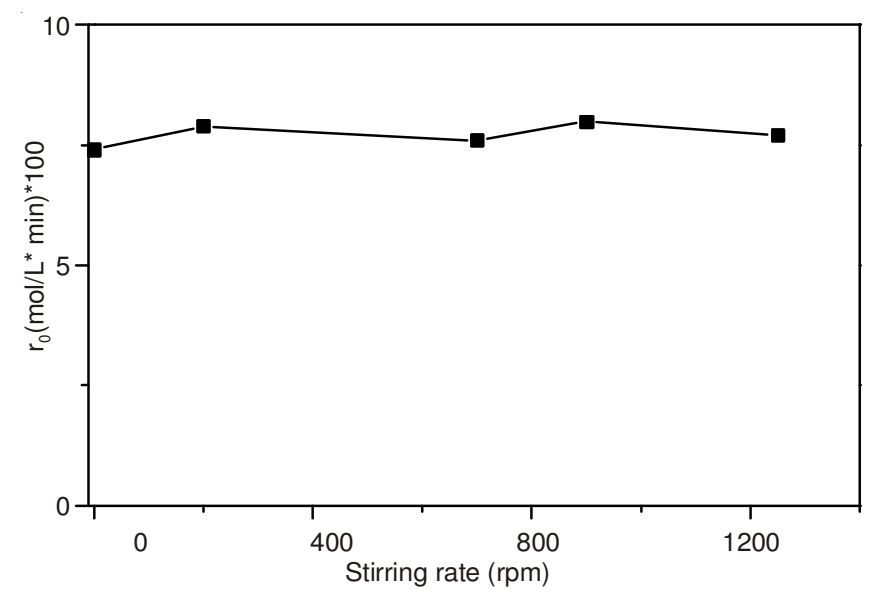

Fig. 5. Initial reaction rates versus different reaction stirring rate

Effect of reactant concentration: Apparent reaction orders were determined by varying the concentration of one reactant while keeping the other in excess and measuring initial kinetics at $55^{\circ} \mathrm{C}$. The results are given in Table- 3 . The concentrations of both acetic acid and methanol had positive effects on the reaction rate with increasing reactant concentration. Using a power law approximation (1.1), the apparent reaction orders were determined to be 0.8 for methanol and 1.0 for acetic acid.

$$
\mathrm{r}_{0}=\mathrm{k}_{0} \mathrm{C}_{\mathrm{A} 0}^{\alpha} \mathrm{C}_{\mathrm{M} 0}^{\beta}
$$

\section{TABLE-3}

INITIAL REACTION RATE FOR THE DETERMINATION OF APPARENT REACTION ORDERS OF ACETIC ACID AND METHANOL IN SNCPSs (80) CATALYZED ESTERIFICATION AT $55^{\circ} \mathrm{C}$ WITH STIRRING RATE OF 1250 RPM

\begin{tabular}{ccc}
\hline $\mathrm{C}_{\mathrm{A} 0}(\mathrm{~mol} / \mathrm{L})^{\mathrm{a}}$ & $\mathrm{C}_{\mathrm{M} 0}(\mathrm{~mol} / \mathrm{L})^{\mathrm{b}}$ & $\mathrm{r}_{0}\left(\mathrm{~mol} / \mathrm{L}^{*} \min \right) * 100^{\mathrm{c}}$ \\
\hline 10 & 10 & 9.8800 \\
3.85 & 19.23 & 7.8385 \\
2.17 & 21.74 & 5.0935 \\
1.36 & 22.73 & 3.2127 \\
15.15 & 3.03 & 7.5152 \\
15.82 & 1.90 & 5.2373 \\
14.20 & 4.26 & 9.6875 \\
\hline
\end{tabular}

${ }^{a} \mathrm{C}_{\mathrm{A} 0}$ the initial concentration of acetic acid; ${ }^{\mathrm{b}} \mathrm{C}_{\mathrm{M} 0}$ the initial concentration of methanol; ${ }^{\mathrm{C}}$ The initial reaction rate

Proposed reaction mechanism: In order to determine whether the adsorption/desorption of acetic acid was comparable to or slower than the surface reaction, experiments using nano-sized protonic acid catalyst (80) pre-saturated with acetic acid before initiating the reaction by charging preheated methanol were carried out (Table-4). The results for esterification at $55^{\circ} \mathrm{C}$ showed no improvement in the initial reaction rate compared with the experiments using the catalyst without pre-adsorbed acetic acid.

\begin{tabular}{|c|c|c|c|}
\hline \multicolumn{4}{|c|}{$\begin{array}{c}\text { TABLE } 4 \\
\text { INITIAL REACTION RATES WITH/WITHOUT } \\
\text { PRE-ADSORPTION IN ACETIC ACID }\end{array}$} \\
\hline SNCPSs (80) & $\mathrm{C}_{\mathrm{A} 0}(\mathrm{~mol} / \mathrm{L})^{\mathrm{a}}$ & $\mathrm{C}_{\mathrm{M} 0}(\mathrm{~mol} / \mathrm{L})^{\mathrm{b}}$ & $\mathrm{r}_{0}(\mathrm{~mol} / \mathrm{L} * \mathrm{~min}) * 100^{\mathrm{c}}$ \\
\hline $\begin{array}{l}\text { Pre-adsorption in acetic } \\
\text { acid overnight }\end{array}$ & 10 & 10 & 7.3 \\
\hline $\begin{array}{l}\text { Without pre-adsorption } \\
\text { in acetic acid }\end{array}$ & 10 & 10 & 8.0 \\
\hline
\end{tabular}

Moreover, the adsorption of methanol is considered. It is based on the consideration that methanol is a strong nuclephile and also competes for the acid site ${ }^{21}$. As mentioned in the polymer swelling part pre-adsorbed methanol also had a negligible effect on the initial reaction rate. Therefore, the surface reaction should be the rate-limiting step due to the rapid reactant adsorption/desorption equilibrium.

Two reactants were involved in the esterification reaction, namely methanol and acetic acid. Therefore pyridine adsorbing experiments were conducted to determine whether single active site or dual active sites involved in the esterification reaction. Before each run, nano-sized protonic acid catalyst (80) was first immersed in the solvent containing methanol and a known amount of pyridine overnight to allow a complete equilibrated adsorption of the organic base on the acid sites of the catalyst. 
The reactor was heated to $55^{\circ} \mathrm{C}$ and then preheated acetic acid was charged into the reactor to initiate the reaction. As shown in Fig. 6, the initial reaction rates decreased linearly with increasing amounts of pyridine, suggesting that single active site involves in the heterogeneous reaction. Otherwise, a non-linear figure should be obtained if dual active sites participated in the esterification reaction.

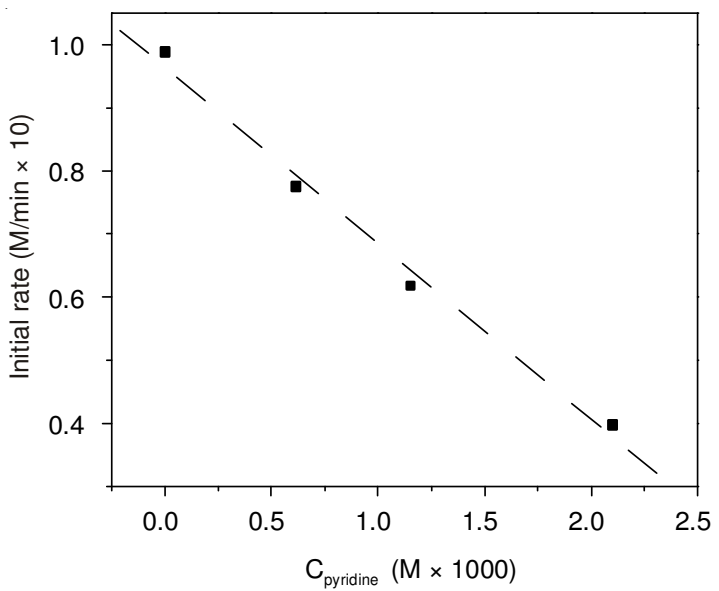

Fig. 6. Pyridine adsorbed SNCPSs (80) catalyzed esterification of methanol with acetic acid

The mechanism of the esterification reaction catalyzed by sulfuric acid (Fig. 7) shows that the oxygen on the carboxylic acid is protonated, thereby activating nucleophilic attach by alcohol ${ }^{22-24}$. In our heterogeneous esterification reaction system, it can be assumed that acetic acid is protonated first, which is attacked by methanol. From the result of pyridine adsorbing experiment, it can be concluded that only single active site was involved in our heterogeneous esterification reaction. Hence, the surface reaction should be the nucleophilic attack of protonated acetic acid by methanol forming ester and water. Hence, rapid reactant adsorption/desorption equilibrium with surface reaction as the rate-limiting step is likely the initial reaction mechanistic paths under our reaction conditions, which were shown in eqns. 2-4.

$$
\begin{aligned}
& \mathrm{A}+\mathrm{S} \underset{\mathrm{k}_{-1}}{\stackrel{\mathrm{k}_{1}}{\rightleftharpoons}} \mathrm{A} \bullet \mathrm{S} \\
& \mathrm{M}+\mathrm{S} \underset{\mathrm{k}_{-2}}{\stackrel{\mathrm{k}_{2}}{\rightleftharpoons}} \mathrm{M} \bullet \mathrm{S} \\
& \mathrm{A} \cdot \mathrm{S}+\mathrm{M} \stackrel{\mathrm{k}_{3}}{\longrightarrow} \text { Product }
\end{aligned}
$$

where A represents acetic acid, $\mathrm{M}$ represents methanol, $\mathrm{S}$ is a vacant acid site on the solid catalyst surface A.S and M.S are molecules adsorbed on the catalytic acid site, respectively.

Modeling kinetics: Fig. 8 shows the conversion of acetic acid catalyzed by sulfuric acid and nano-sized protonic acid catalyst (80) at $55^{\circ} \mathrm{C}$, respectively. The amount of active sites for both sulfuric acid and nano-sized protonic acid catalyst(80) were kept to be the same. It can be seen that the homogeneous acid catalyst shows similar acetic acid conversion as the heterogeneous catalyst within 10 min reaction time. However, after $6 \mathrm{~h}$ the acetic acid conversion for $\mathrm{H}_{2} \mathrm{SO}_{4}$ is higher than that of nano-sized protonic acid catalyst (80). Both catalysts exhibit the same trend for the whole reaction run process.
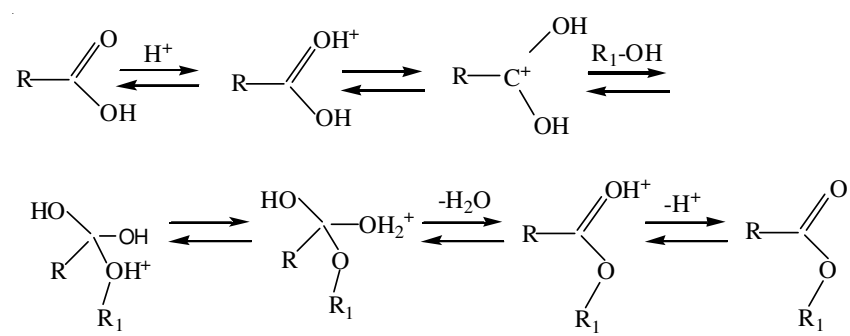

Fig. 7. Mechanistic route of sulfuric acid catalyzed esterification reaction of methanol with acetic acid

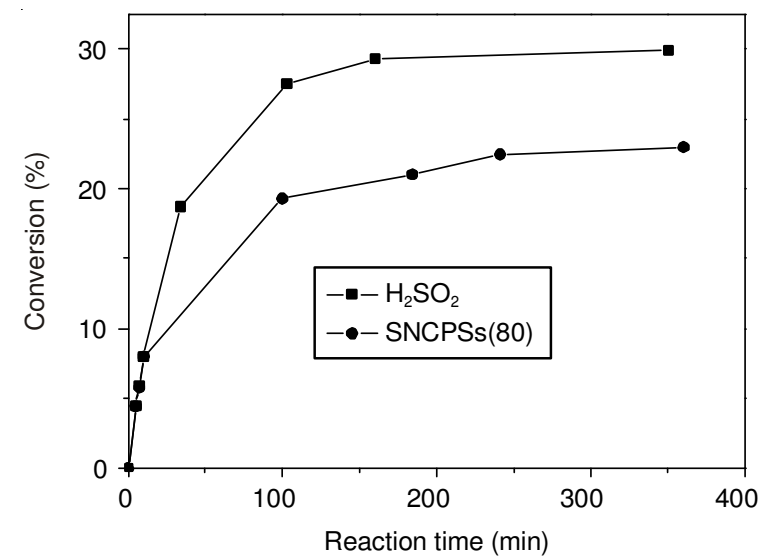

Fig. 8. Acetic acid conversion $v s$. time for esterification reaction catalyzed by $\mathrm{H}_{2} \mathrm{SO}_{4}$ and SNCPSs (80) at $55^{\circ} \mathrm{C}$

As we known water is a byproduct of esterification reaction for methanol with acetic acid, which can inhibit the reaction rate. For sulfuric acid catalyzed esterification reaction for methanol with acetic acid the deactivating effect of water was due to the water solvation of the protons. The loss in acid strength of catalytic protons due to water solvation leads to a decrease in the concentration of protonated carboxylic acid, thus inhibiting the formation of esters ${ }^{22}$. The sulfuric acid and nano-sized protonic acid catalyst (80) had the similar water deactivation profile (Fig. 9).

Based on the experimental observed kinetic data, it is proposed that the esterification catalyzed by prepared nanosize protonic acid catalyst proceeds via mechanism analogous to the homogeneous catalyzed one. By considering the initial reaction period when reverse hydrolysis is not important, the initial set of mechanistic paths are as mentioned in eqns. 5-7:

$$
\begin{aligned}
& \mathrm{A}+\mathrm{S} \stackrel{\mathrm{k}_{1}}{\underset{\mathrm{k}_{-1}}{\longrightarrow}} \mathrm{A} \bullet \mathrm{S} \\
& \mathrm{M}+\mathrm{S} \underset{\mathrm{k}}{\stackrel{\mathrm{k}_{2}}{\underset{\mathrm{k}_{-2}}{\longrightarrow}} \mathrm{M} \bullet \mathrm{S}} \\
& \mathrm{A} \cdot \mathrm{S}+\mathrm{M} \underset{\mathrm{k}_{3}}{\longrightarrow} \text { Product }
\end{aligned}
$$

Using the pseudo-steady-state approximation for the adsorption steps (A.S and M.S) with surface reaction as the rate limiting step, the initial reaction rate can be expressed as:

$$
\mathrm{r}_{0}=\frac{\mathrm{k}_{3} \mathrm{~K}_{\mathrm{A}} \mathrm{C}_{\mathrm{A} 0} \mathrm{C}_{\mathrm{M} 0} \mathrm{C}_{\mathrm{S} 0}}{\mathrm{~K}_{\mathrm{A}} \mathrm{C}_{\mathrm{A} 0}+\mathrm{K}_{\mathrm{M}} \mathrm{C}_{\mathrm{M} 0}+1}
$$

where $\mathrm{k}_{3}$ is the surface reaction constant, $\mathrm{C}_{\mathrm{A} 0}, \mathrm{C}_{\mathrm{M} 0}$ and $\mathrm{C}_{\mathrm{S} 0}$ are the concentrations of acetic acid, methanol and the total acid sites, respectively. $\mathrm{KA}\left(\mathrm{K}_{\mathrm{A}}=\mathrm{k}_{1} / \mathrm{k}_{-1}\right)$ and $\mathrm{KM}\left(\mathrm{K}_{\mathrm{M}}=\mathrm{k}_{2} / \mathrm{k}_{-2}\right)$ 


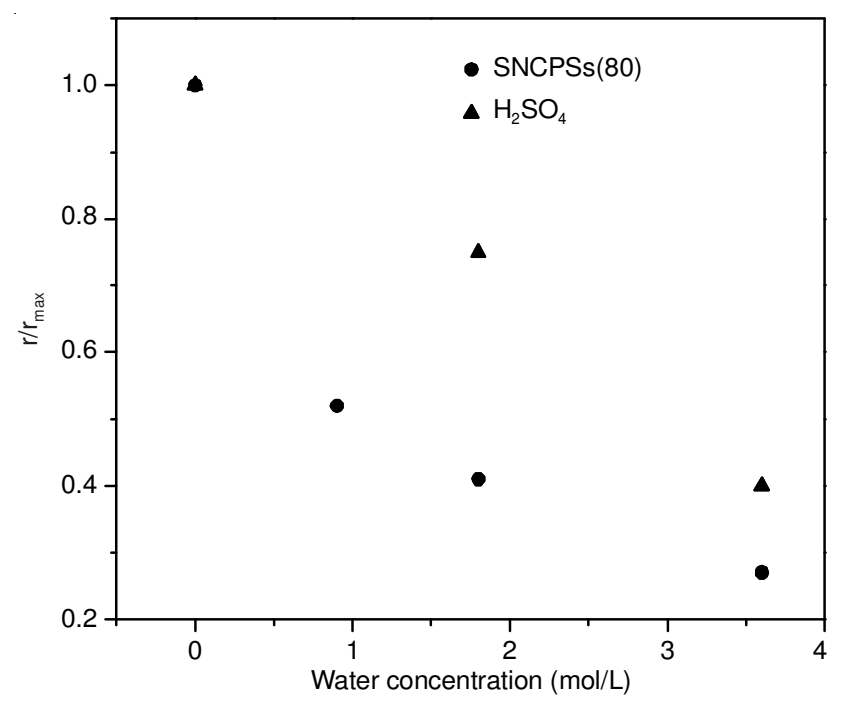

Fig. 9. Water sensitivity of esterification reaction for methanol with acetic acid at $55^{\circ} \mathrm{C}$ on $(-)$ nano-sized protonic acid catalyst (80) and on ( $\boldsymbol{\Delta}$ ) $\mathrm{H}_{2} \mathrm{SO}_{4}$

are the adsorption equilibrium constants of acetic acid and methanol, respectively.

Using eqn. 8 and the initial kinetic data measured at various initial reactant compositions, a mathematical model was developed by curve fitting method using Matlab.

Employing least squares fitting algorithm, the kinetic parameters $\mathrm{K}_{\mathrm{A}}$ and $\mathrm{K}_{\mathrm{M}}$ are estimated to be $0.2(\mathrm{~L} / \mathrm{mol})$ and 0.5 (L/mol), respectively. Figs. 10 and 11 showed the fitting results by plotting $1 / \mathrm{r}_{0} v s .1 / \mathrm{C}_{\mathrm{M} 0}$ and $1 / \mathrm{r}_{0} v s .1 / \mathrm{C}_{\mathrm{A} 0}$, respectively. As can be seen, the mathematical model derived can successfully predict the initial rate data.

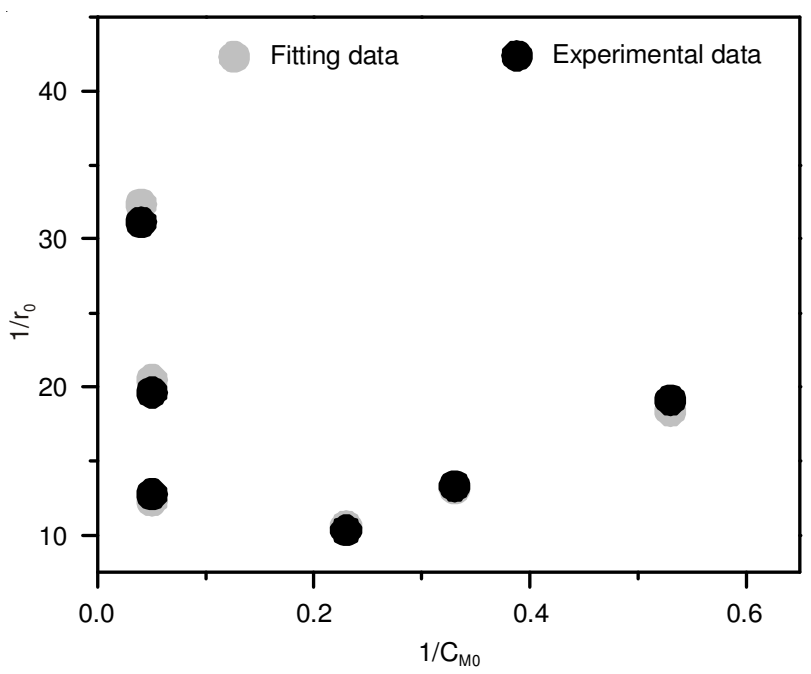

Fig. 10. Comparison of experimental data with predicted data derived from the mathematical model by plot of $1 / \mathrm{r}_{0} v s .1 / \mathrm{C}_{\mathrm{M} 0}$

As discussed earlier, the presence of water can seriously inhibit the catalysis reaction. Hence, the effect of water must be included in the kinetic expression. The initial reaction mechanistic paths with the presence of water are:

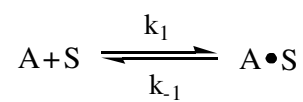

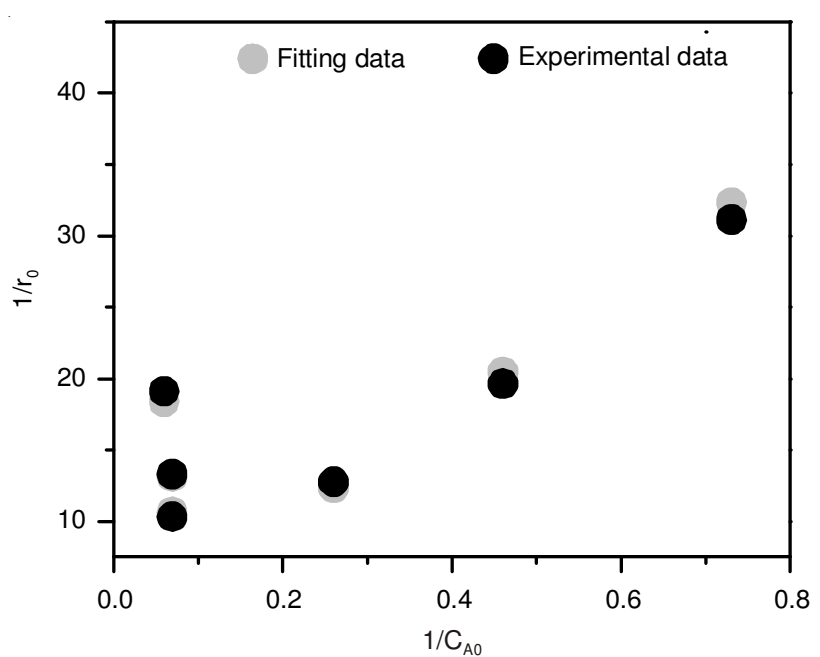

Fig. 11. Comparison of experimental data with predicted data derived from the mathematical model by plot of $1 / \mathrm{r}_{0} v s .1 / \mathrm{C}_{\mathrm{A} 0}$

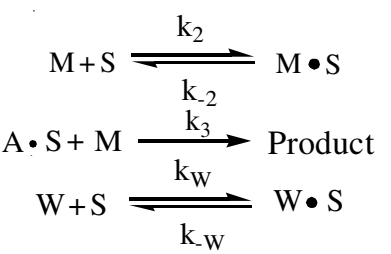

where $\mathrm{W}$ represents water and $\mathrm{W} \cdot \mathrm{S}$ is the adsorbed water. Defining as $\mathrm{K}_{\mathrm{W}}=\mathrm{k}_{\mathrm{w}} / \mathrm{k}_{-\mathrm{w}}$ the adsorption equilibrium constant for water, the rate expression for the presence of initial water is:

$$
\mathrm{r}_{0}=\frac{\mathrm{k}_{3} \mathrm{~K}_{\mathrm{A}} \mathrm{C}_{\mathrm{A} 0} \mathrm{C}_{\mathrm{M} 0} \mathrm{C}_{\mathrm{S} 0}}{\mathrm{~K}_{\mathrm{A}} \mathrm{C}_{\mathrm{A} 0}+\mathrm{K}_{\mathrm{M}} \mathrm{C}_{\mathrm{M} 0}+\mathrm{K}_{\mathrm{W}} \mathrm{C}_{\mathrm{w} 0}+1}
$$

Since $\mathrm{K}_{\mathrm{A}}$ and $\mathrm{K}_{\mathrm{M}}$ are determined previously, hence, the only parameter in eqn. 13 is the adsorption equilibrium constant for water $\mathrm{K}_{\mathrm{M}}$. Rearrange the above eqn. 13, we get:

$$
1 / \mathrm{r}_{0}=\frac{\mathrm{K}_{\mathrm{A}} \mathrm{C}_{\mathrm{A} 0}+\mathrm{K}_{\mathrm{M}} \mathrm{C}_{\mathrm{M} 0}+1}{\mathrm{k}_{3} \mathrm{~K}_{\mathrm{A}} \mathrm{C}_{\mathrm{A} 0} \mathrm{C}_{\mathrm{M} 0} \mathrm{C}_{\mathrm{S} 0}}+\frac{\mathrm{K}_{\mathrm{W}}}{\mathrm{k}_{3} \mathrm{~K}_{\mathrm{A}} \mathrm{C}_{\mathrm{A} 0} \mathrm{C}_{\mathrm{M} 0} \mathrm{C}_{\mathrm{S} 0}} \mathrm{C}_{\mathrm{w} 0}
$$

$\mathrm{K}_{\mathrm{W}}$ can be easily obtained from the plot of $1 / \mathrm{r}_{0} v s . \mathrm{C}_{\mathrm{w} 0}$ as 4.1 $(\mathrm{L} / \mathrm{mol})$. As can be seen from Fig. 12, the model can accurately assess the dependency of reaction rate with the presence of initial water, supporting the estimated water inhibition effect on solid acid catalyst.

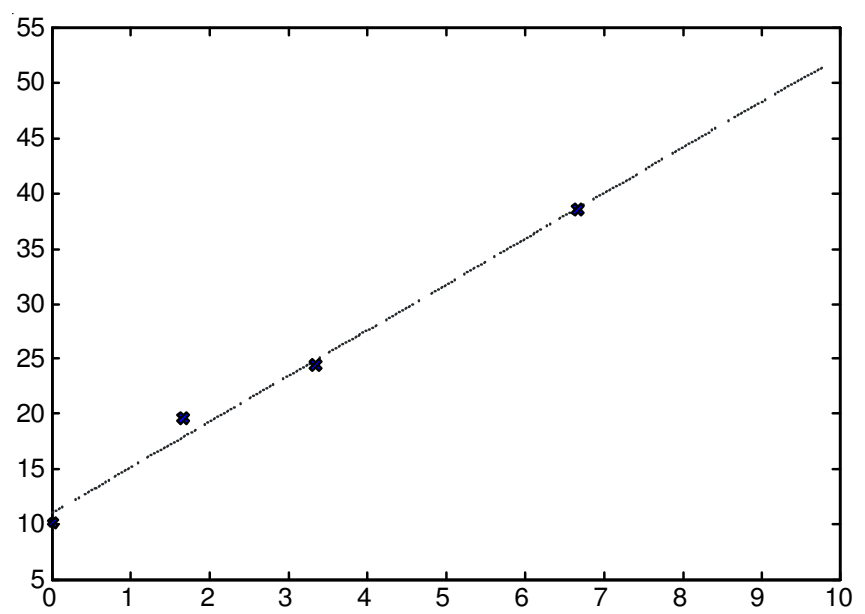

Fig. 12. Dependency of initial reaction rate on the initial water concentration for nano-sized protonic acid catalyst (80) 


\section{Conclusion}

The prepared strong nano-sized protonic acid catalysts show excellent catlaytic performance. The appropriate elevated sulfonation temperature is beneficial for the attachment of $-\mathrm{SO}_{3} \mathrm{H}$ groups onto nano-sized crosslinking polystyrene spheres, which in turn improve the conversion efficiency. The initial rate study showed that the surface reaction should be the rate-limitting step and only single active site was involved in the surface reaction.

\section{ACKNOWLEDGEMENTS}

This work was financially supported by the Science and Technology Innovation Project (Emerging Artists Talents Scheme) of Zhejiang Province (No. 2012R422020 and 2011R422007), the Chinese National Natural Science Foundation (No.11105078 and 21306091), the MoE AcRF Tier 1 grant (R279000224112), the Scientific Research Fund of Zhejiang Education Department (Y201224425), Ningbo Natural Science Foundation (2012A610130), the Zhejiang Province Natural Science Foundation (LQ13E020002).

\section{REFERENCES}

1. P.L. Dhepe, M. Ohashi, S. Inagaki, M. Ichikawa and A. Fukuoka, Catal. Lett., 102, 163 (2005).

2. D. Das, J. Lee and S. Cheng, J. Catal., 223, 152 (2004).

3. A.S. Dias, M. Pillinger and A.A. Valente, J. Catal., 229, 414 (2005).

4. D. Margolese, J.A. Melero, S.C. Christiansen, B.F. Chmelka and G.G. Stucky, Chem. Mater., 12, 2448 (2000).
5. J.A. Melero, R.V. Grieken, G. Morales and V. Nuño, Catal. Commun., 5, 131 (2004)

6. T. Okuhara, Chem. Rev., 102, 3641 (2002).

7. S. Inagaki, S. Guan, T. Ohsuna and O. Terasaki, Nature, 416, 304 (2002).

8. E. Cano-Serrano, J.M. Campos-Martin and J.L.G. Fierro, Chem. Commun., 246 (2003).

9. Q. Yang, M.P. Kappor, N. Shirokura, M. Ohashi, S. Inagaki, J.N. Kondo and K. Domen, J. Mater. Chem., 15, 666 (2005).

10. Q. Yang, M.P. Kapoor and S. Inagaki, J. Am. Chem. Soc., 124, 9694 (2002).

11. M. Hara, T. Yoshida, A. Takagaki, T.I. Takata, J.N. Kondo, S. Hayashi and K. Domen, Angew. Chem. Int. Ed., 43, 2955 (2004).

12. J. Steinmetz, M. Glerup, M. Paillet, P. Bernier and M. Holzinger, Carbon, 43, 2397 (2005).

13. S. Iimura, K. Manabe and S. Kobayashi, Org. Lett., 5, 101 (2003).

14. K. Manabe and S. Kobayashi, Adv. Synth. Catal., 344, 270 (2002).

15. X. Tian, Z. Jiang, L. Zhang, L. Luo and X.S. Zhao, Appl. Mech. Mater., 182-183, 222 (2012).

16. L. Wang, Q. Yan and X.S. Zhao, Langmuir, 22, 3481 (2006)

17. C.R. Martins, F. Hallwass, Y.M.B. De Almeida and M.A. De Paoli, Ann. Magn. Reson., 6, 46 (2007).

18. M.J. Canovas, I. Sobrados, J. Sanz, J.L. Acosta and A. Linares, J. Membr. Sci., 280, 461 (2006)

19. M. Okamura, A. Takagaki, M. Toda, J.N. Kondo, K. Domen, T. Tatsumi, M. Hara and S. Hayashi, Chem. Mater., 18, 3039 (2006).

20. B. Bae, H.Y. Ha and D. Kim, J. Membr. Sci., 276, 51 (2006).

21. H. Mahdioub, S. Roualdes, P. Sistat, N. Pradeilles, J. Durand and G. Pourcelly, Fuel Cells, 5, 277 (2005).

22. Y.J. Liu, E. Lotero and J.G. Goodwin Jr., J. Catal., 242, 278 (2006).

23. R. Ronnback, T. Salmi, A. Vuori, H. Haario, J. Lehtonen, A. Sundqvist and E. Tirronen, Chem. Eng. Sci., 52, 3369 (1997).

24. E. Lotero, Y.J. Liu, D.E. Lopez, K. Suwannakarn, D.A. Bruce and J.G. Goodwin, Ind. Eng. Chem. Res., 44, 5353 (2005). 